Article

\title{
A qualitative research on higher education students' knowledge, attitudes and behavior towards SDG 5, Gender Equality
}

\author{
Ana Lucía Ortega Larrea1, Diana Kingsley-Thomas ${ }^{2}$ and Paula Suárez * \\ 1 ESIC; analucia.ortega@esic.edu \\ 2 ESIC; diana.kingsleythomas@esic.edu \\ * ESIC; paula.suarez@esic.edu
}

\begin{abstract}
A project-based module on Sustainable Development Goal number 5, Gender Equality, was implemented on 5 different groups of Business English students consisting of a total number of 62 students in higher education. The main purpose of this project was to raise awareness of this goal by means of a flipped method in which students were required to carry out some research on specific areas of the aforementioned goal and work in teams to elaborate oral presentations. Once their findings were shared in class, students were expected to answer a written questionnaire of openended questions which were part of a qualitative analysis. Results of this survey showed that not only $90 \%$ of the students gained in depth knowledge of this goal, but also $85 \%$ had built a positive attitude to take initiative and $80 \%$ were optimistic about future gender equality. Finally, $70 \%$ of students suggested further social action to curb the problem of gender discrimination. On the whole, the flipped classroom method of learning combined with project-based group work have proven to be an effective way to raise awareness of this goal, create a more positive attitude, increase their willingness to take action as well as widening their English lexical resources.
\end{abstract}

Keywords: SDG; Gender Equality; project-based methodology.

\section{Introduction}

\subsection{Gender Equality in Spain}

The 2030 Agenda for Sustainable Development drives the international community's commitment to the achievement of gender equality and the empowerment of all women and girls through a specific goal and as well as cross-cutting into other goals (Department of Economic and Social Affairs, UN, 2015). Spanish society continues to face fundamental challenges to achieve real and effective gender equality. Despite it being recognized in the Constitution and in our legal system, and the significant progress made in recent years, discrimination persists, ranging from the most extreme forms -such as those experienced by women victims of violence- to the less perceptible ones that occur on a daily basis in all spheres. In this sense, it is essential to address groups that are victims of multiple discrimination, often hidden until now, such as women and girls with disabilities. (Ministerio de Derechos Sociales y Agenda 2030, 2020).

As a matter of fact, as demonstrated by the Women's Institute for Equal Opportunities (IMIO) of the Ministry of Equality, inequality between women and men persists in all areas of Spanish life. Through the National Institute of Statistics, quantitative studies have been carried out, in which the results show persistent inequalities in unemployment, types of salaries, contracts, access to education, health, reconciliation between work and family, access to science, technology and information, victims of violence, and above all, in empowerment and access to decision-making. (Instituto Nacional de estadística, INE, 2020).

Spanish academia might assume that middle- and upper-class students at a private university have received enough education in their lives to understand not only why 
gender equality is a fundamental aspect on the road to a world of sustainable development but that they have also internalized the concept of goal number 5 in their lives: "Achieve gender equality and empower all women and girls". However, the sample of this study showed that it is still necessary to raise awareness of Sustainable Development Goal number 5, especially if one considers that they are studying so as to occupy key positions in the management, communication, marketing and advertising of companies. Indeed, their awareness, attitudes and behaviour will have a decisive influence on the future direction of the Spanish economy.

\subsection{Project Based and Flipped Classroom}

Previous literature state the benefits of project-based methodology to increase enthusiasm and motivation of foreign language learners in higher education (Villalobos, 2014). In addition, reviewed literature insists on teaching English for Specific Purposes (ESP) based on real-world problems since content-based projects foster not only critical thinking skills (CTS) (Liaw, 2007) but also more creative ideas (Robijah Kamarulzaman, 2016).

Likewise, the most recent conclusions on second language teaching methodology, in the monograph published by the Spanish Ministry of Education and Vocational Training, The flipped classroom model: a challenge for student-centered teaching, confirms that the flipped-classroom methodology favours student-centered teaching, encourages student reflection on their own learning process and, above all, engages students in a more personal context for learning (Touron et al., 2021).

Students at ESIC University are used to interacting in classrooms where contentbased projects and flipped methodologies have become their regular context of learning English for Specific Purposes. Nevertheless, the fact that they had to answer an online survey on the Agenda 2030, and more specifically, on SDG 5, has helped them become conscious of what they have learned and how this project has changed their attitude and behaviour

\subsection{Objectives}

The main objective of this study is to raise awareness of the implementation of Sustainable Development Goal 5, as stated and developed by the United Nations on its website, among first- and second-year university students at ESIC University, studying Business, Marketing, Publicity and Digital Data Management. As in Gündüz's study, awareness raising is not limited to the dissemination of knowledge but seeks a change in the attitude and behaviour of university students. Likewise, following the Gündüz study, the aim is to determine whether the educational differences of our students make a significant difference in their attitude and behaviour to promote gender equality in their private and professional spheres. (Gündüz, 2017)

The purpose of Gündüz's quantitative study aligns with the fourth of the transformative measures of the Action Plan for the Implementation of the Government of Spain's Agency 2030: "Inform to know. Raise awareness to do. Communicate to transform" (Gobierno de España, 2018). Although the present study is not quantitative but qualitative, and on a smaller scale, it also deduces that information is ineffective unless it manages to change the attitude and behaviour of university students.

\section{Methodology}

\subsection{Settings}

The sample consisted of 62 first- and second-year university students, aged between 18 and 20, enrolled in English for Specific Purposes (ESP) in Business and Administration, Data Science, Marketing, Publicity and Public Relations degrees. Of the 65 initial students, 3 students did not answer the questionnaire, and of the 62 who completed the study, 36 were female and 16 were male. The context of the study is a private university focused on business, its main target being middle- and upper-class students, many of whom, due to 
the economic crisis caused by the pandemic, have sought financial aid from the scholarships that the university grants to students with academic excellence, large families, siblings studying at the same university, disability, and students from abroad and from other Spanish cities who have to pay for residence fees and living expenses. None of the six classes studying English for Specific Purposes (ESP) exceeded fifteen students. Although students were not asked if they had a scholarship, more than thirty students provided this information in the open-ended questions. Student data were collected with a code to protect students' rights, following the ethical criteria recommended by Uwe in qualitative studies (Flick, 2010).

\subsection{Design and Evaluative Framework}

The phases of the project were threefold: 1) lecture of content providing information on the SDGs and explaining the basis for the flipped classroom that would be evaluated; 2) oral presentations given by students and taking on the role of a teacher; explaining a section of SDG 5 to their peers; 3) online response to a one-hour questionnaire of openended questions.

In the first phase, students were given a keynote presentation entitled "Sustainable Development Goals: Transforming our World". The content focused on the history of the United Nations, its agencies, the origin of the SDGs in the Millennium Development Goals (2015), and reasons as to why it is necessary to change the world. Subsequently, they were briefed on the seventeen goals, paying attention to how the United Nations organizes the information on its official website: Presentation of Goal 5, reasons why it is crucial in a sustainable world, Facts and Figures, Targets and Links. Finally, each class was divided into groups of 2 or 3 students and allocated a specific area of SDG Goal 5 on the official website to explore, thus avoiding repetition. Students' research would later be presented to the other members of the class.

In the second phase, flipped classroom, students tried to build on new knowledge acquired in the previous presentations. Each class followed the following content division scheme: group 1: brief explanation of the 17 SDGs; group 2: detailed overview of goal 5; group 3: goal 5 facts and figures; group 4: targets of goal 5; and group 5: explore news, videos and links of goal 5. Each group contributed information but, at the same time, asked questions which gave way to an interactive context.

After five flipped classroom sessions, the students on an individual basis underwent an online test consisting of open-ended questions that they were asked to develop in paragraph form. Students were given the freedom to answer or dismiss any questions as well as encouraged to explain as much as they wanted to. According to Lucerne Declaration, individuals' knowledge, attitudes, behaviour and perception and values are crucial for sustainable development (IGU-UGI, 2007), and thus, our open-ended questions tried to find out if the project-based activity on SDGs, and more specifically on Goal 5, had managed to have an impact on students' knowledge, behaviour and attitude. For this purpose, two different sets of questions were given where questions regarding knowledge, attitude and behaviour were mixed. In this way, this qualitative approach was both inductive (based on previous theory) and deductive (based on students' answers); as well as nomothetic (pointing to general and common tendencies) and idiographic (reflecting on individuals' statements) at the same time. (Gibbs, 2018)

\section{Findings}

Most answers, from short to long ones, were related to how students had widened their knowledge of the SDG 5, which suggests that students are more comfortable expressing what they learn, rather than commenting on their impressions and attitudes. The most frequently dismissed questions were those asking about possible behavioral changes in their family context and professional future. Only $38 \%$ of the students knew about the existence of SDG before this project-based activities, and $24 \%$ admitted that they had 
heard about the SDGs but that the project together with the flipped classrooms helped them acquire a better understanding.

Student no29: "If poverty, hunger and good health are solved first, the these (SDGs) will pave the way for the other goals."

Student no12: "Education is the key to end gender inequality, and it should start at school."

Student 36: "Education and cooperation together are the key, instead of wars about anything."

Students 48: "You must educate the young and re-educate the older generation, because unless we change our mentality, this (equality) will never happen, and it will take ages to happen."

Student no5: "The governments are the solutions to inequality in each country and unless they change their attitudes, this problem will not be solved world-wide."

Student 50: "Support brands that try to create awareness such as Benetton. Believe this can be achieved."

As regards to SDG, $5,90 \%$ of the students stated they had gained in depth knowledge of this goal. Thus, student ํㅡㄹ 29 concludes "culture and religion are the cause of gender mutilation"; another student states: "I think SDG no.5 is important because it helps you understand important issues such as genital mutilation, which should be finished globally." Student 22: "I have learned so much about this topic, which made me realize how blind folded I was."

Although Spanish students wrote longer responses about what they had learned and fewer sentences about their expectations, $80 \%$ showed themselves optimistic about future gender equality.

Student 61: "each person has a way of thinking and acting, so it is not so easy to solve this issue, but hopefully the day will come when all women feel equal to men, and men who do not see equality now, will see it."

Student $\mathrm{n}$ - 7: "...little by little, things will improve."

Student $\mathrm{n}$ 18: "From my point of view, it is like a balance that has been tilted in favor of men for a long time and to achieve their equality there is probably to tilt her in favor of women for a while. I trust and I have the faith and the hope of an early equality on that scale."

Notwithstanding the most frequently dismissed questions being those referring to possible behavioral changes in their family context and professional future, $70 \%$ of students suggested further social action in different ways:

Student $\mathrm{n}^{\circ}$ 38: "We should facilitate the incorporation of women into the workplace as many have to choose between their careers and their children."

Student $\mathrm{n}$-62: "Gender inequality is in process to be fixed. I 'll make a social campaign with shocking pictures that make the society reflect about the situation and also raise awareness about that."

It is worth noting that although the teachers in this study at no time mentioned the need to favor feminist mobilizations, $10 \%$ of female students did in fact suggest mobilization as an effective solution. This suggests that the urgency of women's mobilization addressed in previous literature is taking hold among future professionals (Sen, 2019). For example, student no 18 stated: "I hope this issue will be solve in a near future, I think we are fighting to solve it because women know how to team up in order to achieve their feminist targets."

On the whole, $85 \%$ had built a positive attitude to take initiative and showed their willingness to work towards a more sustainable future, without focusing only on SDG 5. For instance, a student $\mathrm{n}^{\mathrm{o}} 22$ replied that she believed a better world could be achieved and citizens should support brands that try to create awareness such as Benetton. Similarly, student $\mathrm{n}^{\mathrm{o}} 58$ stated: "I think all the ideas mentioned in class are quite important as they all talk about issues that we should improve as soon as possible such as sustainability, the goals we have for 2030, gender equality in all situations, etc. I want to contribute to improving the world through my work."

A possible limitation of the study is that students of English for Specific Purposes are developing their communication skills in a second language. Hence, they expressed themselves as effectively as possible, which would differ if done so in their mother tongue. 
Despite their language limitation, differences in their background did not seem to affect the results. There were 4 students from South America and 5 from other European countries. However, no meaningful differences among the answers of students with diverse educational background were found. In this regard, the results from this study align with Güzüz's findings once again. Perhaps, the only significant difference which could be mentioned affects gender itself: the number of male-students who were pessimistic about future gender inequalities was two times higher than the number of female-students who did not believe gender inequalities could be solved worldwide by the year 2030should discuss the results and how they can be interpreted from the perspective of previous studies and of the working hypotheses. The findings and their implications should be discussed in the broadest context possible. Future research directions may also be highlighted.

\section{Conclusions}

Although the sample of this study was initially aimed to analyze the project-based content and flipped classroom methodologies, the fact that students were asked whether this type of activities increased their awareness towards global problems led them to reflect upon their own way of learning favorably. Indeed, not only did students realize how class activities helped them to widen their knowledge but also improve their attitude and willingness to take action on sustainability.

Furthermore, the majority of students became engaged in the topic of the 2030 Agenda, as a way to learn English for specific purposes when they realized that sustainability would somehow have an impact on their professional career. Interestingly, there was no significant difference in the replies by students from foreign countries, thus culture does not appear to be a relevant variable. The survey also revealed that $90 \%$ had gained in depth knowledge of this goal; $80 \%$ showed themselves optimistic about gender equality in a near future, and $85 \%$ felt ready to take initiatives in order to improve sustainability. Different suggestions were provided by students in order to curb the problem of gender discrimination, such as having more conscious governments, raising awareness as early as primary schools, reducing poverty, fighting for humans' rights in general, etc. These solutions were openly discussed in flipped classes. However, although neither teachers nor students mentioned women's mobilizations openly, $10 \%$ of female students advocated for women's mobilization in their written replies.

Author Contributions: Conceptualization, Ana Lucía Ortega Larrea and Paula Suárez; methodology, Diana Kingsley-Thomas.; formal analysis, Diana Kingsley-Thomas; investigation; resources, Ana Lucía Ortega Larrea and Paula Suárez; data curation, Diana Kingsley-Thomas; writing - original draft preparation, Ana Lucía Ortega Larrea; writing-review and editing, Diana KingsleyThomas ; supervision, Ana Lucía Ortega Larrea. All authors have read and agreed to the published version of the manuscript.

Funding: This research received no external funding.

Acknowledgments: We would like to thank the Vice-Rector's Office for Research at ESIC for facilitating and promoting this qualitative study. We would also like to thank the students who participated actively in class and in the survey, for their enthusiasm and willingness to learn.

\section{References}

Department of Economic and Social Affairs, UN. (2015). Transforming our world: the 2030 Agenda for Sustainable Development. (U. Nations, Ed.) Retrieved 5 29, 2021, from https://sdgs.un.org/2030agenda

Flick, U. (2010). An Introduction to Qualitative Research. London, UK: SAGE.

Gibbs, G. (2018). Analyzing Qualitative Data (2nd ed., Vol. 6). SAGE Publications Ltd. 
Gobierno de España. (2018, June 29). Plan de Acción para la Implementación de la Agenda 2030. Hacia una Estrategia Española de Desarrollo Sostenible. (D. G. Sostenible, Ed.) Retrieved May 29, 2021, from http://www.exteriores.gob.es/portal/es/saladeprensa/multimedia/publicaciones/documents/plan\%20de\%20accion\%20para\%20la\%20implementacion\%20de\%20la\%20agenda\%202030.pdf

Gündüz, S. (2017). A Research about Attitudes and Behaviours of University Students with Having Different Cultures towards the Environment through Sustainable Development. EURASIA Journal of Mathematics Sicience and Technology Education, 13((6)), 18811892. doi:10.12973/eurasia.2017.01206a

IGU-UGI. (2007). Lucerne Declaration on Geographical Education for Sustainable Development. In H. Haubrich, S. Reinfried, Y. Schleicher, \& A. Remplfler (Ed.), Proceedings of the Lucerne-Symposium. 42, pp. 243-250. Lucerne, Switzerland: Geographiedidaktische Forschungen. Retrieved July 21, 2021, from https://www.iau-hesd.net/sites/default/files/documents/lucernedeclaration.pdf

Instituto Nacional de estadística, INE. (2020). Mujeres y Hombres en España. Retrived May 29, 2021, de https://www.ine.es/ss/Satellite?param1=PYSDetalleGratuitas\&c=INEPublicacion_C\&p=1254735110672\&pagename=ProductosYServicios\%2FPYSLayout\&cid=1259924822888\&L=1

Liaw, M. L. (2007). Content-based reading and writing for critical thinking skills in an EFL context. English Teaching and Learning, 3 (2), 45-87.

Ministerio de Derechos Sociales y Agenda 2030. (5 de May de 2020). Objetivo 5. Retrived May 29, 2021, de Igualdad de Género : https://www.agenda2030.gob.es/objetivos/objetivo5.htm

Robijah Kamarulzaman, Z. A. (2016). Creating Thinking Classrooms: Perceptions and Teaching Practices of ESP Practicioners. In Elsevier (Ed.), International Confernce on Teaching and Learning English as an Additional Language, GlobELT 2016, 14-17 April. 232, pp. 631-639. Antalya: Elsevier. doi:10.1016/j.sbspro.2016.10.087

Sen, G. (2019, January). Gender Equality and Women's Empowerment: Feminist Mobilization for SDGs. Global Policy, Volume 10 (Supplement 1 ). doi:10.1111/1758-5899.12593

Touron, Javier; Díaz, Celia Maya; Iglesias, Javier; Giménez, Xavier; Martín, Debora; Tourón, Javier; Navarro, Enrique; Sousa, Susana; Peset, Maria José; Muñoz-Sepúlveda, Jesús; Prieto, Alfredo; Barbarroja, José; Álvarez, Susana; Alfredo Corell, Mercedes IndaCaro. (2021). Monographic issue: The flipped classroom model: a change for student-centered teaching. Revista de Educación, 391.

Villalobos, O. B. (2014, August). Content-Based Instruction: A Relevant Approach of Language Teaching. Innovaiones educativas, 15(20), 71-84. doi:10.22458/ie.v15i20.515 